\title{
Iva FERLINC
}

\section{Kolizej: Rušitev ali prenova?}

Vroča tema preteklega leta na področju arhitekturnega in urbanističnega načrtovanja je vsekakor projekt za Novi Kolizej. Z menjavo lastnika, se pravi podjetja Kolizej, je propadajoča stavba $v$ središču Ljubljane postala predmet polemike med zagovorniki zaščite Kolizeja in zagovorniki njegove rušitve. Problem, s katerim se spopadamo že vrsto let, je obnova Kolizeja. Od izgube svoje prvotne funkcije propada na dnu nekdanje gramozne jame, ki jo je ljubljanski magistrat dodelil arhitektu Withalmu. Že od nekdaj je bil namenjen zbiranju socialno šibkih prebivalcev Ljubljane. S preurejanjem in dograditvami je bila podoba spomenika vedno bolj okrnjena, izginile so arkade in okrasje, del objekta se je celo porušil zaradi nespametnega preurejanja. Primer spretne obnove dediščine in oživljanja mestnega jedra je pri naših sosedih, gre za muzej Kunsthaus v Gradcu, kjer se stara arhitektura povezuje z novo. Morda se rešitev ponuja $v$ združevanju interesov.

\begin{abstract}
Last year's hot topic in the area of architectural and urban planning in Ljubljana has got to be the New Kolizej project. Due to a change in ownership, the decapitated building in the centre of town has become a topic of discussion, pitting conservationists against demolitioners. The problem stems from the many renovations that the Kolizej has received over the years. Since loosing its initial function, which was given to it by architect Withalm and the Ljubljana magistrate, the Kolizej has slowly, but surely, been falling apart. For many years now, the building has become a meeting point for the socio-economically less privileged. Moreover, with various renovations and additions that have been done over the years, the heritage site has slowly but surely been stripped of its initial purpose. Various design features have disappeared, and a part of the structure has even fallen down due to poor remodelling. As an example of a successful renovation of a cultural heritage site and an outstanding rehabilitation of a city centre, one has got to look no further than ones neighbour, the Kunsthaus museum in Graz. There one can see old and new architecture adjacent to each other. Perhaps that is the solution, the merger of various interests in one edifice.
\end{abstract}

\author{
Kulturna \\ dediščina \\ Kolizej \\ Gradec \\ Kunsthaus \\ Cultural heritage \\ Kolizej \\ Graz \\ Kunsthaus
}

\section{Zgodovina Kolizeja [1]}

Kolizej je zgradil avstrijski arhitekt in tovarnar Josef Benedikt Withalm, ki je prišel iz Gradca v Ljubljano leta 1840 na povabilo mestnega župana J. Hradeckyga, da bi postavil stavbo za vojaška stanovanja. Mestna občina je Withalmu dala stavbišče zastonj, to je bila opuščena gramoznica tedaj zunaj mesta, in gradnja se je začela leta 1845. Stavba je bila glede na velikost končana $\mathrm{v}$ rekordnem času pozimi leta 1847. Nastala je po zgledu sedem let starejšega Kolizeja (Coliseum) v Gradcu, ki danes ne stoji več.[2] Odprtje Kolizeja je bilo na silvestrovo leta 1845 , dva dni pozneje so ga za- prli, da so lahko končali vsa dela, in ga znova odprli 16. maja.

Kolizej je v prvi vrsti uporabljala vojska, ki se je selila iz Avstrije prek Ljubljane v Italijo. V stavbi je lahko prenočevalo do 3000 vojakov. S tem so bili prebivalci odrešeni dolžnosti omogočanja prenočišč avstrijskim vojakom. Withalm, vojska in mesto so imeli bogato korespondenco zaradi stalnih medsebojnih zahtev tako vojske kot lastnika. To je že vse od začetka povzročilo prezidave in preureditve. Preostala ponudba $\mathrm{V}$ Kolizeju je bila precej pestra. Ljudje so zahajali vanj na razne plesne in glasbene prireditve ter proslave, zbirali so se $\mathrm{v}$ pivnici in restavraciji. Tudi okolica je bila zelo urejena. Glavni vhod v gostilno je bil s Koli- zejske (danes Puharjeve ul.), s Celovške je vodil vhod v koridor poleg gostilne. Zraven gostilne so bili terasa za goste ter vrtovi za sprehod. V plesni dvorani, ki je imela tri galerije, so prirejali pustne zabave, loterije, razstave, karnevale starih oblek, modne revije, igrala je kolizejska godba v graških uniformah.

Ob dograditvi je bil Kolizej daleč največja stavba v Ljubljani, namenjena zabavi. Prva večja stavba v njegovi bližini je bila leta 1851 zgrajena evangeličanska cerkev. Kolizej je bil takrat daleč od mestnega središča, kljub temu pa je bil dobro prometno povezan in je bil del ljubljanskega življenja. Bil je v bližini ceste za Celovec, $\mathrm{z}$ nasadi pa je bil povezan tudi s Tivolijem. 
Skoraj dve leti po odprtju je bil zaradi neupoštevanja varnostnih predpisov lastnika 18. decembra 1847 v požaru delno uničen. Poslopje je bilo sicer zavarovano za 24.000 goldinarjev, škode pa je bilo za okoli 50.000 goldinarjev. Mestne oblasti so se takoj začele zavzemati, da bi pomagale Withalmu pri obnovi. Stavbo so kmalu res obnovili in nekoliko preuredili, niso pa nadomestili fasadnih arkad.

Po smrti arhitekta Withalma leta 1865 je Kolizej podedoval njegov sin Josef. Leta 1866 je stavba prišla pod ljubljansko mestno policijo. Ostala je v lasti rodbine Withalm do leta 1906, ko so jo prodali podjetju Gebrüder Dedhendhi, Malusa \& co. Nato jo je kupila rodbina Heinrihar s kupoprodajno pogodbo in postala lastnica celotnega Kolizeja s priležnimi zemljišči. Franc Heinrihar je stavbo po nakupu za takratne razmere moderniziral, zlasti ko je opremil vse pode s parketom iz svoje tovarne. Vanjo so se vselili obrtniki in manjši proizvajalci ter trgovska podjetja. Kmalu so gradnja pravih kasarn, večje zahteve vojske in premajhen dobiček lastnika privedli do opuščanja prvotne namembnosti Kolizeja in tako je leta 1890 s prezidavanji postal hiša $\mathrm{z}$ najemniškimi stanovanji z okrog 520 stanovalci, zato so najprej preuredili nadstropja, nato pa še klet.

\section{Polemika}

Natečaj za Novi Kolizej je vnel burno razpravo med konservatorji, umetnostnimi zgodovinarji, arhitekti, urbanisti in zagovorniki natečaja ter rušenja Kolizeja z investitorjem na čelu.

\subsection{Argumenti ohranitve}

Kolizej je z Odlokom o razglasitvi spomenikov naravne in kulturne dediščine na območju občine Ljubljana Center med Aškerčevo, Tivolsko in Slovensko cesto (Ur. list RS,
29. 10. 1993, št. III/60, str. 2937-2944) razglašen za arhitekturni spomenik lokalnega pomena, od 26. septembra 2005 pa državnega pomena. Prepovedana so vsa obnovitvena dela, ki bi škodovala spomeniku ali ga kazila, sploh pa je prepovedana njegova rušitev.

Kolizej je pomembna arhitektura, ker pomeni odmik od tipizirane uradniške arhitekture cesarskega Dunaja, značilne za prvo polovico 19. stoletja, in začetek uvajanja historičnih elementov na objektih. Je prva stavba v Ljubljani, ki se lahko ponaša $\mathrm{z}$ neogotskimi in neoromanskimi prvinami ter je edini ohranjen primer romantičnega historizma, sloga, ki se je razvil proti sredini stoletja. Fasada je minimalno členjena, zaradi česar je močno poudarjena kubičnost stavbne mase. Kolizej je tudi edinstveni primer dinamično členjene »labirintske« stavbe. [3]

Kolizej je zaznamoval urbanizacijo SZ dela Ljubljane. Pred gradnjo je tam ležala opuščena gramozna jama, okrog katere so se razprostirali vrtovi. Arhitekt Withalm je od mesta Ljubljana dobil posest zastonj in začel načrtovati tedaj največjo stavbo, namenjeno zabavi.

Kolizej je ostal v svoji zvrsti arhitekture edinstven. Withalm je namreč zgradil na Dunaju in v Gradcu podobna objekta $\mathrm{z}$ enako funkcijo, a ne stojita več.

\subsection{Argumenti proti gradnji Novega Kolizeja}

Natečaj za Novi Kolizej je spregledal vse veljavne zakone, predpise in navodila o organiziranju natečajev. $\mathrm{V}$ zakonsko zavezujočem urbanističnem dokumentu je za omenjeno lokacijo predpisana obveznost javnega natečaja. O njem govori zakon o graditvi objektov (ZGO). Investitor mora javni natečaj izvesti v sodelovanju s poklicno zbornico, torej Zbornico za arhitekturo in prostor Slovenije (ZAPS). Skupaj določita tip natečaja: nacionalni, mednarodni, vabljeni, s predselekcijo itd., skupaj pa izbereta tudi žirijo. Pri Kolizeju je bil natečaj razpisan v nasprotju z ZGO in natečajnim pravilnikom ter brez sodelovanja pristojne zbornice.

Z gradnjo Novega Kolizeja bi Ljubljana pridobila še eno stolpnico, tokrat kar 25-nadstropni objekt, s katerim si želi investitor povečati dobiček. Vendar pa lokacija vsekakor ni primerna, saj ne samo da bi Novi Kolizej nastal na spomeniku, temveč bi bil zgrajen v središču mesta, ki ga ne bi smeli nadgrajevati z novimi višinskimi poudarki. Poleg tega bi popolnoma zasenčil okoliške stavbe $z$ določeno višino venca, ki zaznamujejo četrt. Ljubljana je že od daleč prepoznavna po svojem obrisu, nova stolpnica pa se zagotovo ne bi ujemala $z$ njim.

Novi Kolizej je urbanistično zgrešen projekt. Zaradi velikosti objekta se postavlja vprašanje, kdo bo uporabljal vse pisarniške prostore. Poleg tega se bo zaradi povečanja delovnih mest na tem območju povečal promet ob konicah, in čeprav je predvidena velika garažna hiša, se bo Ljubljana ob vpadnici Celovški cesti dušila v prometu.

Novi Kolizej je le sestavljenka dveh objektov arhitekturnega biroja Neutelings Riedijk Arhitekti. Junija 2005 je v Hribarjevi dvorani Ljubljanskega gradu potekala razstava maket NRA, kjer so bili predstavljeni vsi njihovi večji projekti. Zelo podoben Novemu Kolizeju je projekt palače pravosodnega in notranjega ministrstva v Haagu, iz katerega ni bil odvzet le osnovni kompozicijski princip, ampak kar celotna pojavnost. Gre za dva stolpa, ki sta stopničasto ožena proti vrhu, postavljena sta zrcalno, namenjena pa sta pisarnam obeh ministrstev. Oklepata osrednji odprti atrij, kjer se srečujejo komunikacije in skupni programi. Kolizeju je podobna tudi koncertna dvorana $\mathrm{v}$ Bruggeu, od koder je povzeta in izpeljana ideja za notranje gledališče. 


\subsection{Argumenti rušenja}

Kolizej je nevaren za bivanje. Po poročilu Zavoda za gradbeništvo iz leta 2004 [4] je objekt zaradi navlaževanja, preobremenitev in neustreznega poseganja $\mathrm{v}$ nosilno konstrukcijo $\mathrm{v}$ zelo slabem stanju. Stavba ni ne potresno ne požarno varna. Zavod za zdravstveno varstvo opozarja, da se v objektu zbirajo golobi, ki prenašajo bolezni. Kosovni odpadki, ki ležijo na dvorišču, privabljajo glodavce. V greznico na severni strani objekta so poleg fekalij speljane še meteorne vode, kar po strokovnem navodilu o urejanju gnojišč in greznic ni dovoljeno. Včasih se zato vode celo prelivajo na prosto.

Doslej je veljalo, da je bil arhitekt Withalm nadvse inovativen pri uporabi sodobnih materialov, kot je lito železo pri nosilnih stebrih, vendar se je po najnovejših raziskavah izkazalo, da so v resnici leseni, s čimer je Withalm še pripomogel $\mathrm{k}$ propadanju Kolizeja.[5] Uporabil je tudi cenene okraske, ki so prilepljeni na fasado. Gre torej za bidermajerski kič, ki je nastal hitro in poceni s poglavitnim ciljem, da prinese $\mathrm{v}$ kratkem času kar največji dobiček. Arhitekturno je v Kolizeju le malo izvirnosti.

\section{Primerjava $\mathrm{z}$ graškim Kunsthausom}

Za primerjavo bi navedla mesto Gradec v Avstriji, ki je podobno kot Ljubljana zasnovano pod mestnim gričem ob reki. Ko je Gradec leta 2003 postal evropska kulturna prestolnica, so v njem potekali najrazličnejši projekti, ki so popestrili življenje Gradčanov. Najzanimivejši arhitekturni projekt pa je vsekakor nov muzej sodobne umetnosti Kunsthaus. Zgrajen je bil po načrtih arhitektov Petra Cooka in Colina Fourniera, ki prihajata iz Londona. Objekt Kunsthausa ali »prijazni vesoljček«, kot mu pravijo, je nadvse nenavadna konstrukcija, oblečena v posebno stekleno površino, po kateri potekajo svetlobni napisi. Njegova oblika je podobna napihljivi blazini, iz katere štrlijo nosnicam podobna okna. Površina je svetleča in odseva okoliške stavbe.

Kunsthaus je bil zgrajen $v$ povezavi z Eiserneshaus arhitekta Withalma. Delno propadajočo stavbo Železne hiše so spretno preuredili v sklopu novega muzeja, tako da so oba objekta povezali $\mathrm{z}$ mostom.[6] $\mathrm{Ne}$ samo da jim je uspelo rešiti stavbo izjemnega pomena za avstrijsko kulturo, gre namreč za eno prvih stavb, zgrajenih z litoželezno konstrukcijo v Evropi, temveč so izredno originalno povezali staro arhitekturo $\mathrm{z}$ novo in središču mesta dodali svežino. Kmalu je Kunsthaus postal simbol Gradca.

Gradec je lep primer, kako spretno se da popestriti mestno življenje $\mathrm{z}$ novo arhitekturo, ki je $\mathrm{v}$ tem primeru nadvse drzna. Po drugi strani pa arhitekta nista posegala v višino, saj bi tako skazila prvotno podobo mesta, nad katerim dominira grad. Novi muzej je skrit med okoliške stavbe, ne bode v oči že od daleč. Ko pa se bližamo središču mesta, tik preden prečkamo most čez Muro, nas preseneti svetleča se gmota nenavadne arhitekture. Lahko bi rekli, da se muzej nikakor ne vklaplja v prostor, v katerem prevladujejo baročne, klasicistične in historične stavbe, toda drzna stvaritev daje mestu svoj čar.

Za ljubljanski Kolizej bi bilo morda najprimerneje, da investitor in odgovorne službe sklenejo kompromis, kako območje preurediti. Kolizeja kljub vsemu ni treba rušiti. Treba bi bilo znova izpeljati natečaj, tokrat po legalni poti, kjer bi imeli arhitekti nalogo smiselno združiti staro arhitekturo z novo, povezati Kolizej $\mathrm{z}$ ravnjo mesta in ohraniti gabarite kareja. Preureditev notranjosti bi se morala podrediti programu, ki bi ga v stavbi izvajali. S tem bi investitor izrazil spoštovanje do dediščine, spome- niškovarstvena služba pa bi dopustila zasebniku pri razvoju mesta.

Iva Ferlinc, univ. dipl. um. zgod.

Fakulteta za humanistične študije Koper, Univerza na Primorskem

E-pošta: iva.ferlinc@gmail.com

\section{Opombe}

[1] Obsežnejši pregled zgodovine Kolizeja v: Gojanovič, J. (1988) Kolizej - poskus vračanja mestnih funkcij in likovne zaznavnosti (kare Prešernova-Gosposvetska-Župančičeva-Puharjeva), (diplomsko delo), UL, FAGG, Ljubljana.

[2] O graškem Kolizeju več: Stare, L. (1999) Withalmov "Coliseum « v Gradcu - 7 let starejši brat ljubljanskega »Kolizeja«, Ljubljana, 1999.

[3] O arhitekturi 19. stoletja: Prelovšek, D. (1976) Ljubljanska arhitektura v prvi polovici 19. stoletja, Sinteza, št. 36/37/1976, str. 41-56; Prelovšek, D (1998) Stavbarstvo 19. stoletja in iskanje narodne identitete, Umetnost na Slovenskem, 1998, str. 245-262; Prelovšek, D. (1979) Arhitektura 19. stoletja v Sloveniji, Arhitektov bilten, št. 42/1979, str. 34-35.

[4] Lutman. M. (2004) Analitična ocena varnosti objekta Kolizej v Ljubljani na podlagi pregleda in preiskav nosilnega zidovja ter analize potresne odpornosti, Zavod za gradbeništvo Slovenije, Ljubljana.

[5] Takšno mnenje je izrazil dr. P. Krečič v članku Prestolnica brez stolpnic $v$ Delu (Sobotna priloga, 22. 1. 2005), str. 22-23.

[6] O prenovi Železne hiše v Gradcu: Zechner, M (2001) Reiz Stoff Vechsel, Die Geschichte des Eisernes Hauses und seiner Restaurirung, Gradec.

\section{Viri in literatura}

Ažman Momirski, Lucija (2005) Novi Kolizej v Ljubljani: Vprašanja programa, Urbani izziv, I. 16, št. 1, str. 13-20.

Ferlinc, I. (2005) Kolizej, rušitev ali prenova (diplomsko delo), UL, FF, Ljubljana.

Gojanovič, J. (1988) Kolizej - poskus vračanja mestnih funkcij in likovne zaznavnosti (kare Prešernova-Gosposvetska-Župančičeva-Puharjeva), (diplomsko delo), UL, FA, Ljubljana.

Zechner, M (2001) Reiz Stoff Vechsel, Die Geschichte des Eisernes Hauses und seiner Restaurierung, Gradec.

Zakon o varstvu kulturne dediščine (ZVKD). Zakon o graditvi objektov (ZGO).

Režek, M (2005) Konservatorski program za posege v kulturni spomenik, EŠD 379 Ljubljana - Palača Kolizej, ZVKDS, OE Ljubljana, Ljubljana.

Neutelings, J. W. (2004) At work: Neutelings Riedijk Architects, Rotterdam. 